\title{
MIXED SCLEROSING BONE DYSTROPHIES
}

\author{
Two Case Reports
}

\author{
Geoffrey F. Walker, London, England \\ From the Department of Surgery, University College, Ibadan, Nigeria, \\ and the Institute of Orthopaedics, Royal National Orthopaedic Hospital, London and Stanmore
}

Many of the sclerosing bone dystrophies fall within the classification employed by Fairbank (1951). However, patients occasionally present features suggesting a possible relationship between osteopoikilosis (spotted bones), osteopathia striata (striated bones, Voorhoeve's disease), melorheostosis (running wax bones) and osteopetrosis (dense or marble bones).

Areas of dense bone arranged in different patterns are characteristic of these conditions, which are frequently symptomless, and which are usually detected only by radiography. The variations which may be encountered in sclerosing bone dystrophies impose limitations on their classification, and these mixtures merit further consideration.

A patient is reported here in whom the diagnosis probably falls among the mixed sclerosing bone dystrophies because characteristics of osteopoikilosis, osteopathia striata and melorheostosis were revealed by radiography.

A second patient with a similar mixed sclerosing dystrophy, previously reported by Trevethick in 1953 as a case of melorheostosis, is also described.

\section{CASE REPORTS}

Case 1-A twelve-year-old Etik girl from Eastern Nigeria was admitted to University College Hospital, Ibadan, in 1962 with painful deformities of the lower limbs. At birth the only apparent abnormalities were two crossed toes and a deformed finger. When she began walking at two years of age it was noticed that, in one foot, only the toes touched the ground. By the age of four both feet had an equinus deformity. At eleven other joints developed painful contractures and she was unable to walk or stand unaided. She had attended school until that time and had been keeping up with her contemporaries. She had not menstruated. Apart from the painful deformities there were no other symptoms on admission.

There was no family history of the disorder. Her mother and two brothers were alive and well. Her father had died some years before, probably from old age.

The patient was an alert girl of normal intelligence. There were contractures of all the limbs including the hands and feet, but those in the lower limbs were more severe (Fig. 1). The head, neck, trunk and skin were normal.

The height was four feet nine inches (145 centimetres), the weight was sixty-five pounds (29.5 kilograms) and the chest expansion was two inches (5.1 centimetres).

The lower limbs were unequal in length. The right tibia was ten and a quarter inches (26 centimetres) in length and the left was twelve and three-quarter inches ( 31 centimetres). The right femur was thirteen and three-quarter inches ( 35 centimetres) in length and the left was sixteen and a half inches ( 42 centimetres). The right foot was three-quarters of an inch ( 1.9 centimetres) shorter than the left. The right patella was dislocated laterally and could not be reduced. The right lower femoral epiphysis was enlarged.

In the hips there was 45 degrees loss of extension in the right and 20 degrees loss in the left. The right knee lacked 60 degrees of extension and the left 10 degrees. There was a fixed equinus in both ankles and deformed second and fourth toes on the right (Fig. 2).

In the upper limbs the shoulders were normal. Both the elbows lacked 20 degrees of flexion, and there was slight limitation of supination and pronation. Both the lower radial 
epiphyses were slightly enlarged (Fig. 3) and the wrists were held in ulnar deviation and flexion; there were deformities of the fingers of both hands.

The central nervous system was normal, apart from a slight generalised loss of power in the legs and an absent left triceps reflex. The pulse rate was 104 per minute and the blood

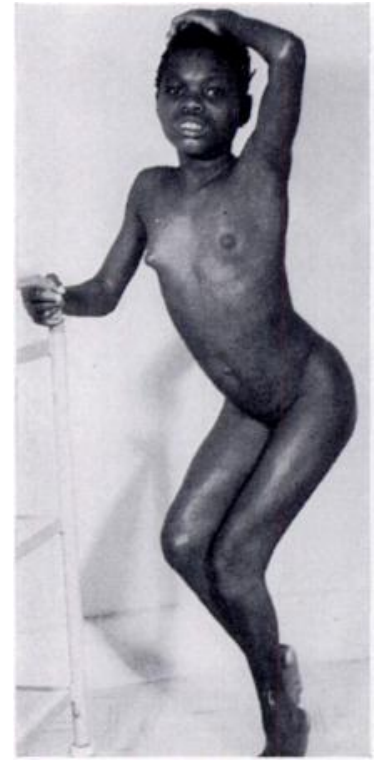

FiG. 1

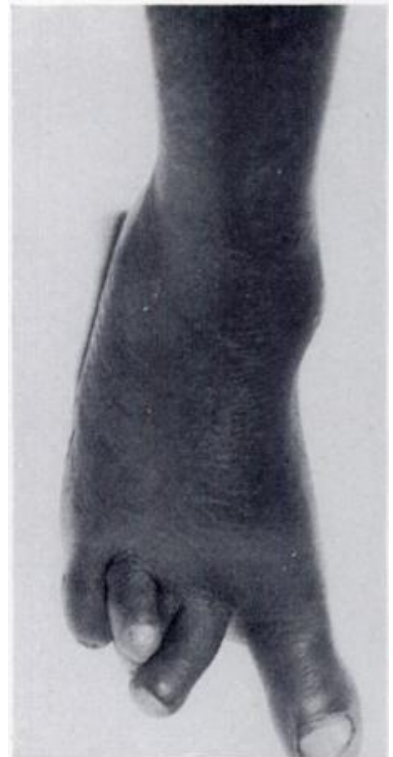

Fig. 2

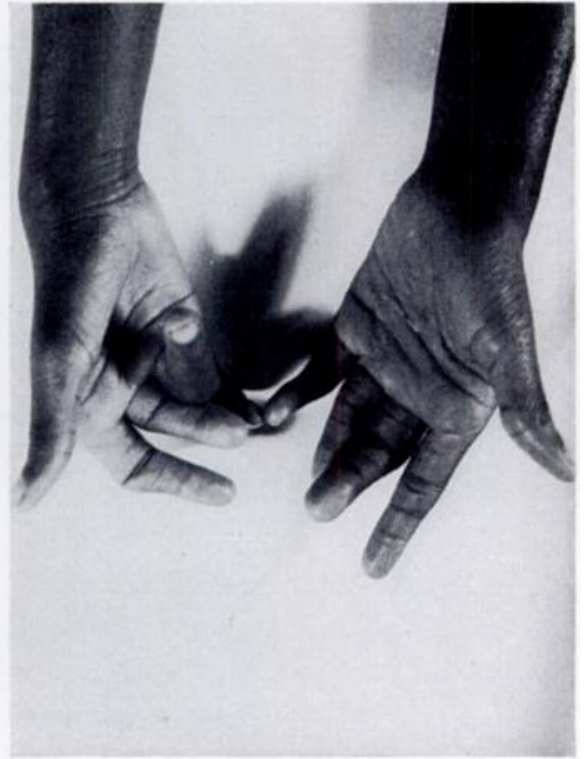

FIG. 3

Case 1. Figure 1-Flexion deformities of knees and hips and equinus deformities of the feet. Figure 2-The toe deformities. Figure 3-The deformities and contractures of several fingers of both hands.

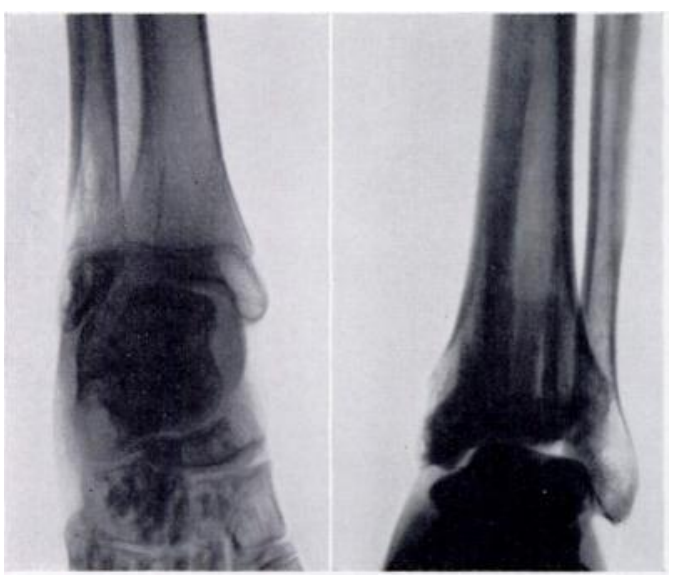

Fig. 4

FIG. 5

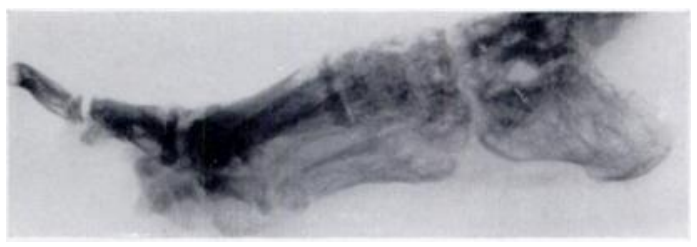

FiG. 6

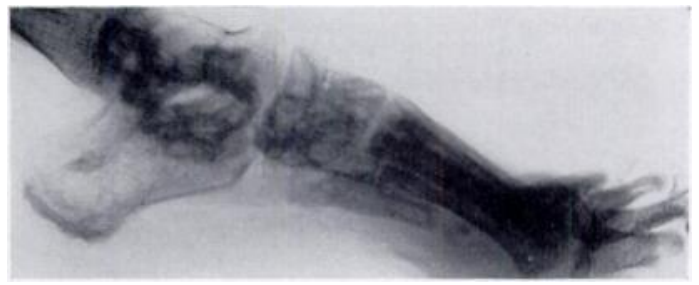

FiG. 7

Case 1. Figure 4-A radiograph of the right foot and ankle showing many small discrete sclerotic areas, like those of osteopoikilosis, in the lower fibular epiphyses and the tarsal bones. Figure 5-The radiograph of the left ankle shows linear sclerotic striations in the lower tibia; while discrete dense areas are apparent in the lower epiphysial region of the tibia and in the talus. Figures 6 and 7 are radiographs of both feet showing the multiple discrete sclerotic areas.

pressure was $120 / 85$ millimetres of mercury. The liver, spleen and kidneys were not palpable. Examination of the eyes by $\operatorname{Dr} \mathrm{S}$. Tompkins revealed no cataract or other abnormality.

Investigations. Skeletal survey-Areas of sclerosis were present in the pelvis, long bones. carpus and tarsus, and in some of the fingers and toes (Figs. 4 to 11). Many small sclerotic

vol. 46 B, NO. 3, AUGUST 1964

$\mathbf{M}_{(4)}$ 


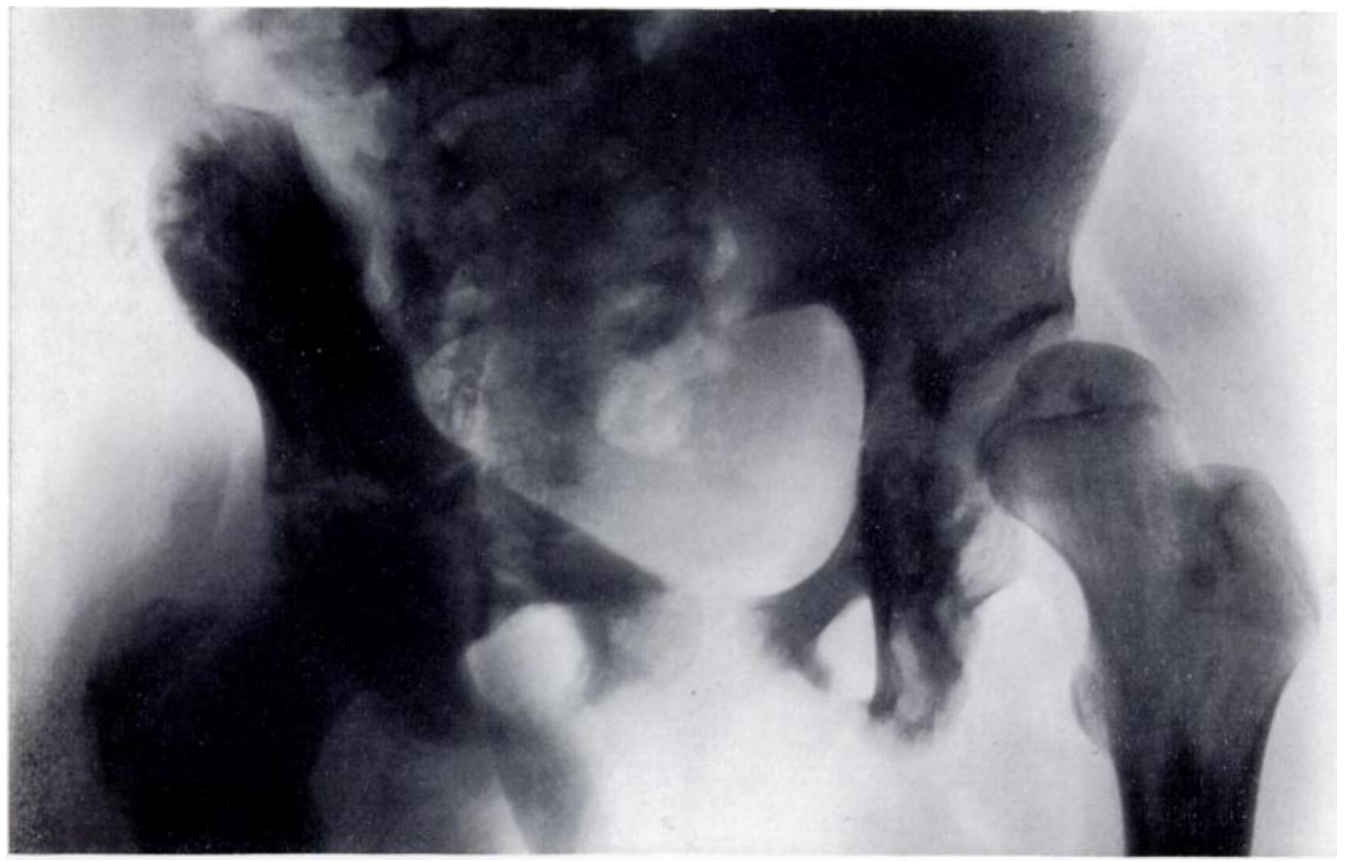

FIG. 8

Case 1-Radiograph of the pelvis with apparent deformities due to hip flexion contractures. There are many small discrete sclerotic areas, particularly around the hip joints, with linear striations in the upper left femur.

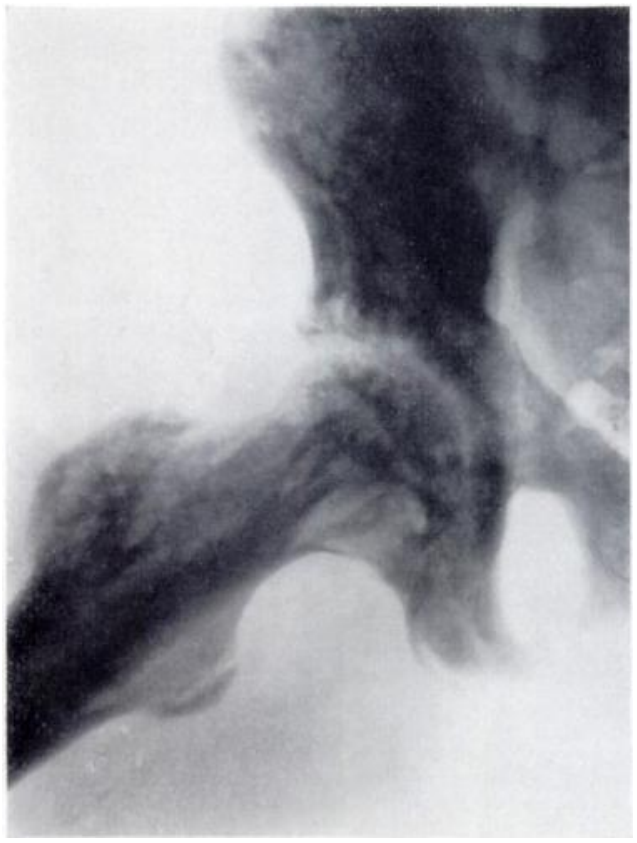

FIG. 9

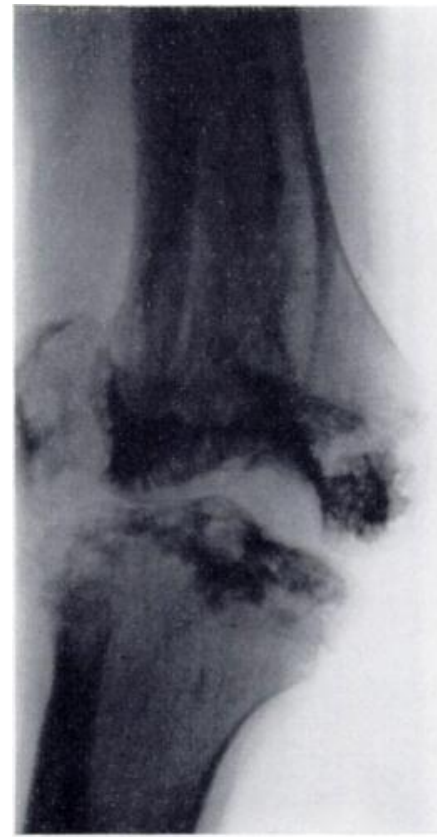

Fig. 10

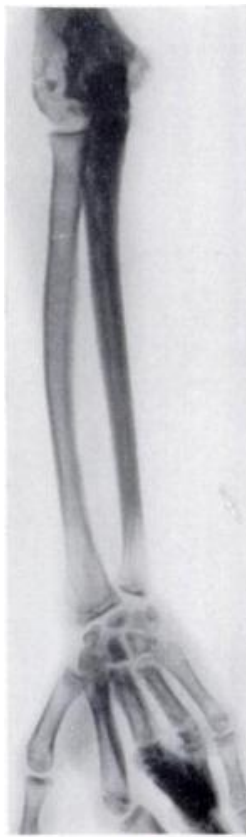

Fig. 11

Case 1. Figure 9-A lateral radiograph of the right hip confirms the presence of small sclerotic areas, and also reveals linear sclerosis in the neck and proximal shaft of the femur. Figure 10 is a radiograph of the contracted right knee. The patella is dislocated laterally. There are sclerotic areas in the tibial and femoral epiphyses, and linear striations in the distal femur. Figure 11 is a radiograph of the left arm which has many changes resembling osteopoikilosis around the elbow and dense sclerosis of the cortex of the ulna. Sclerotic changes are also apparent in the bones of the hand: the second metacarpal bone suggests melorheostosis, with dense sclerosis confined to one side of the bone. The right forearm was similar. The metacarpals are of irregular size and shape and there are minor erosions at some of their bases. 
areas suggestive of osteopoikilosis were present in the bones of the wrists, ankles, feet and the lower ends of both humeri. They were also abundant around the right hip and knee, and were seen in both epiphyses and metaphyses. Linear areas of sclerosis were visible in the distal part of the right femur, left upper femur and right tibia. These markings were like those seen in osteopathia striata, although less well defined than in a classical case of Voorhoeve's disease.

The shafts of several of the limb bones, particularly both ulnae, showed many larger areas of sclerosis. This increased density mainly involved the cortex of long bones and was apparent in all four limbs. It closely resembled melorheostosis in the right fourth metacarpal where it was situated along one side of the shaft.

TABLE I

HaEMatological Findings

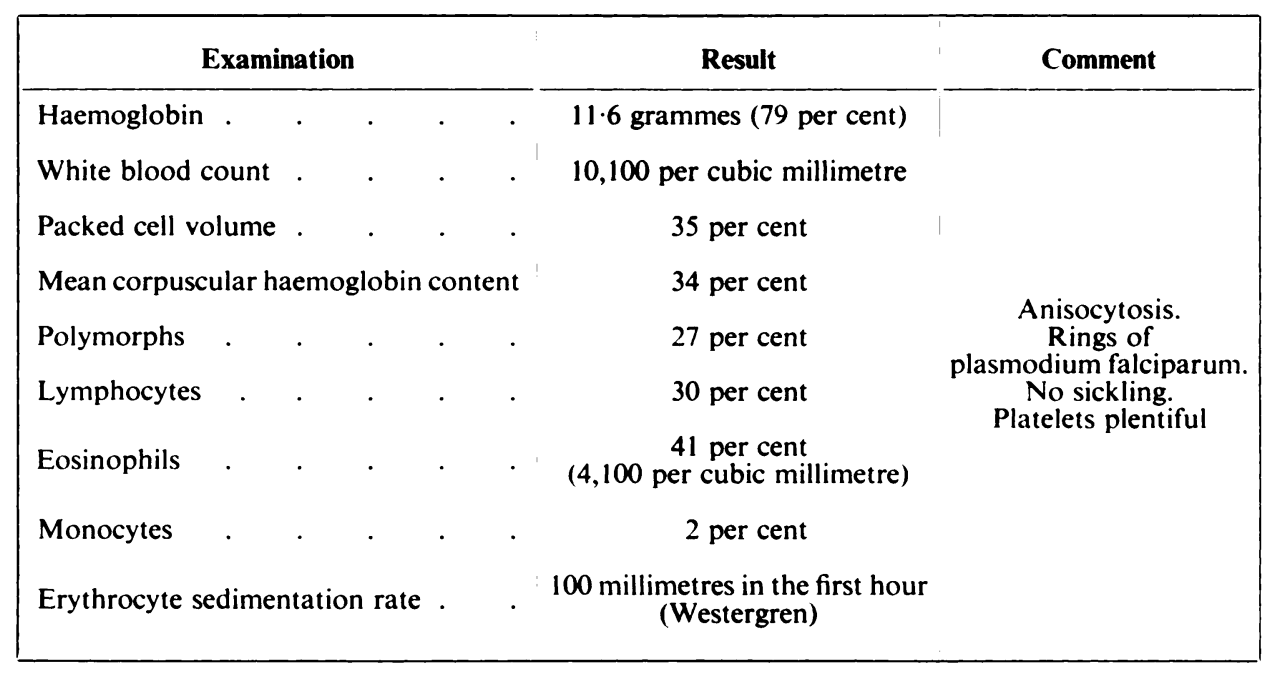

TABLE II

Serial Observations of Eosinophilia and Sedimentation Rate

\begin{tabular}{|cccccc|}
\hline Date & $\begin{array}{c}\text { Total white cells } \\
\text { cer } \\
\text { cubic millimetre }\end{array}$ & $\begin{array}{c}\text { Total eosinophils } \\
\text { per } \\
\text { cubic millimetre }\end{array}$ & $\begin{array}{c}\text { Percentage } \\
\text { of } \\
\text { eosinophils }\end{array}$ & $\begin{array}{c}\text { Erythrocyte } \\
\text { sedimentation rate } \\
\text { in first hour }\end{array}$ \\
\hline August 8 & & & & 96 \\
September & 3 & 15,450 & 18,600 & 83 & \\
September 6 & 9,750 & 16,200 & 60 & 98 \\
September 11 & 7,950 & 9,900 & 80 & 70 \\
\hline
\end{tabular}

A small amount of subperiosteal bone formation was visible along the shafts of the right radius and ulna. The significance of this was not apparent.

There were changes in shape among the metacarpal bones, with shortening and broadening, together with irregularity of the cortex at the bases of some of their shafts. There were no abnormalities in the skull, spine or thorax.

Haematology-Examination of the blood on admission revealed a high eosinophilia and a greatly increased sedimentation rate (Table I). At first these abnormalities were thought to be caused by hookworm infestation, but even after adequate treatment the eosinophilia and erythrocyte sedimentation rate persisted (Table II).

Vol. $46 \mathrm{~B}$, No. 3, AUGUST 1964

$$
M-1_{(8)}
$$




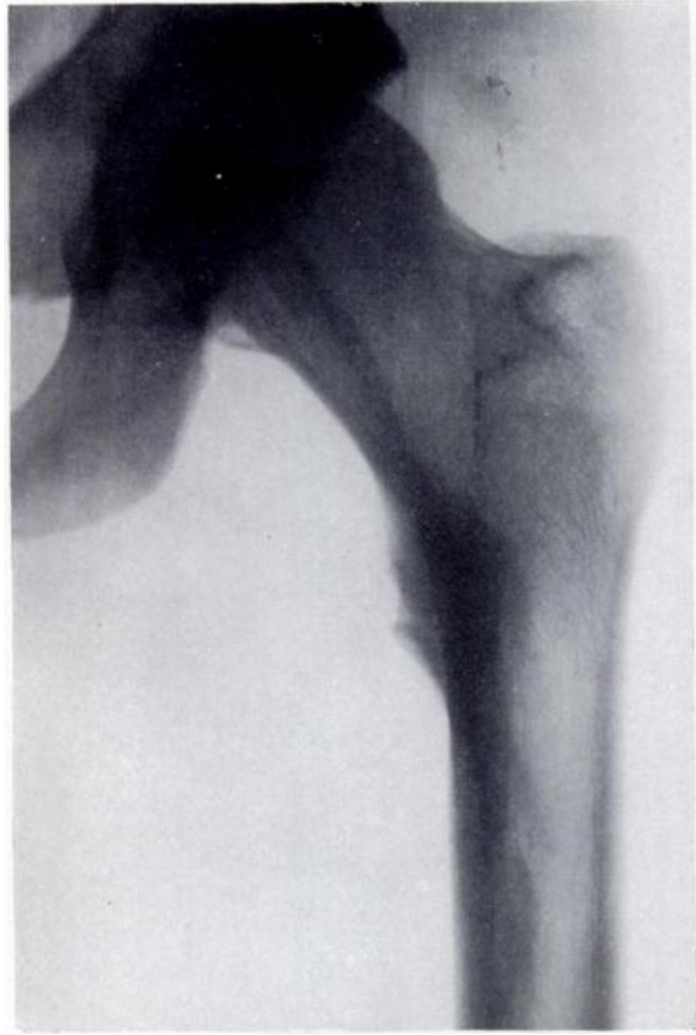

Fig. 12

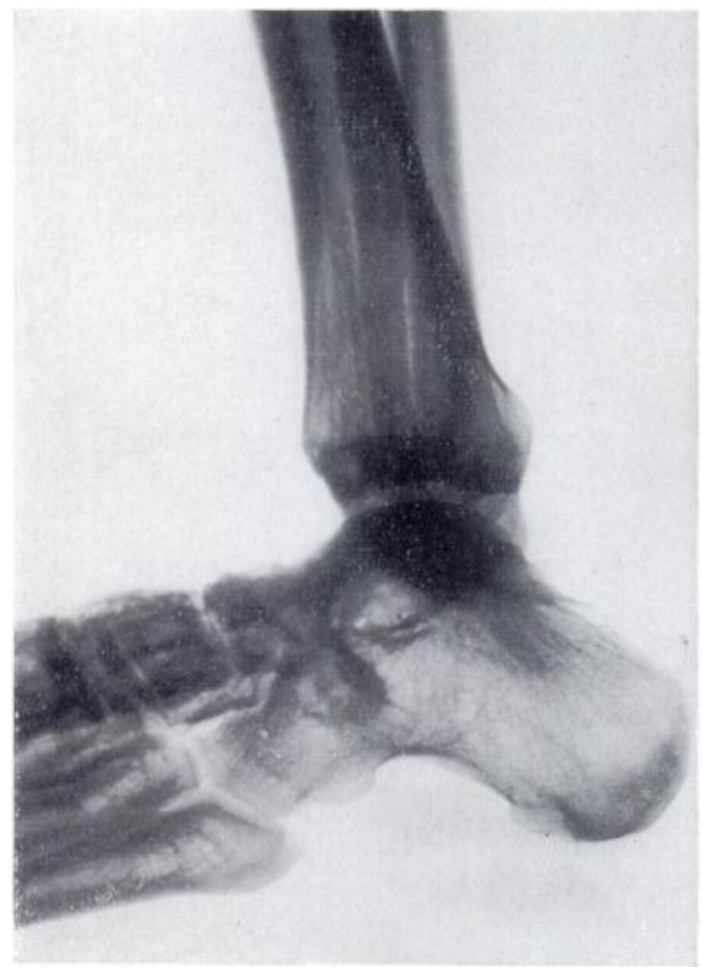

Fici. 14

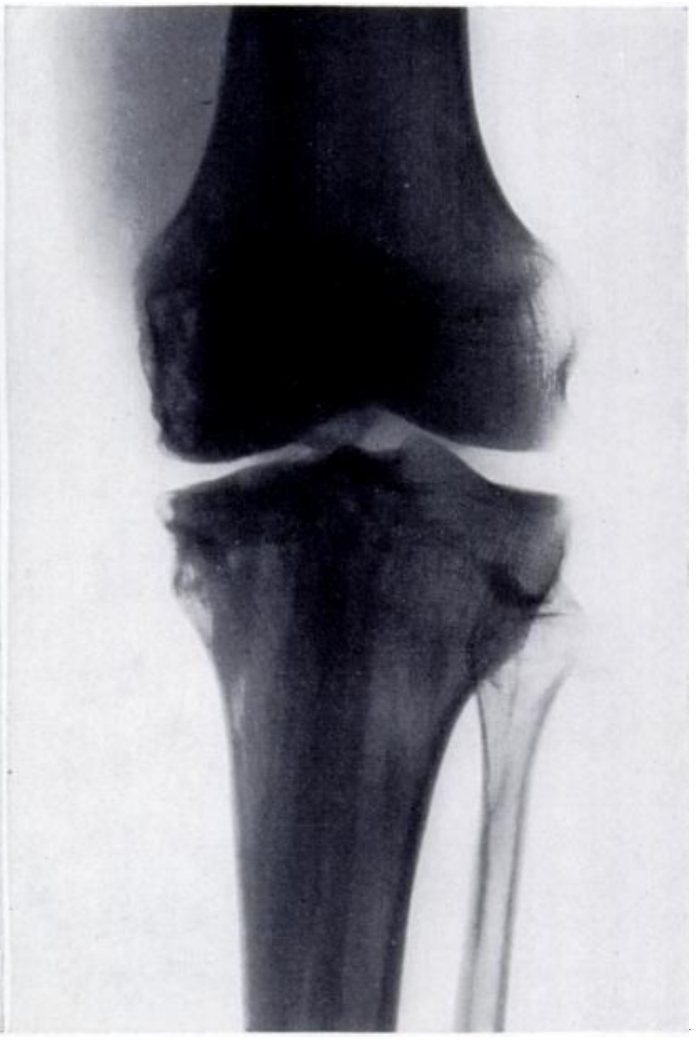

FIG. 13

FIGS. 12 To 14

Case 2-Figure 12 shows a radiograph of the proximal half of the left femur, with obvious sclerosis of the medial cortex of the neck and shaft typical of melorheostosis. In the radiograph of the left knee (Fig. 13) the linear sclerosis has become more widespread and resembles osteopathia striata rather than melorheostosis. The radiograph of the left ankle (Fig. 14) shows changes very like those seen in the ankles and feet of Case 1 (Figs. to 7). In the lower tibia there are vertical striations, and tarsal bones contain discrete sclerotic areas which suggest osteopoikilosis. (Note the subtalar fusion.) 
Other investigations-Estimations of the serum calcium and phosphorus, and of the acid and alkaline phosphatase, were normal on three occasions. The liver function was normal, as was the cerebrospinal fluid. The Kahn test was negative; the blood urea was 23 milligrams per 100 millilitres; the serum uric acid was 2.8 milligrams per 100 millilitres; her blood group was $O$, rhesus positive; the haemoglobin electrophoretic pattern was AA. There was no abnormality in the urine; and skin snips were negative for onchocerciasis. Biopsy material taken from the gastrocnemius muscle was reported by Dr J. G. Jackson as being normal.

A piece of the periphery of the right femoral epiphysis and the adjacent epiphysial plate was removed, and examined microscopically by $\mathrm{Dr} \mathrm{H}$. A. Sissons. The epiphysial nucleus contained some localised areas of abnormally dense bone without any specific histological features. The peripheral part of the epiphysial cartilage plate showed some evidence of growth retardation, but no other significant histological abnormality. The surface of the articular cartilage was covered by a layer of dense fibrous tissue representing the fibrous ankylosis.

Case 2-A nineteen-year-old man injured his left knee while pulling on a rope (Trevethick 1953). His left leg was found to be two inches shorter than the right. A subtalar fusion had been done at the age of four following an attack of pneumonia. Because a radiograph of the injured knee showed unusual sclerotic areas the remainder of the skeleton was radiographed. The changes, which closely resemble those in Case 1, were found only in the left leg.

In the proximal half of the femur melorheostosis was suggested (Fig. 12); around the knee and in the tibia there were vertical striations like those seen in osteopathia striata (Fig. 13).

The bones of the foot showed smaller sclerotic areas very like those seen in the feet of Case 1. While insufficiently distinct for classical osteopoikilosis they do, however, resemble the discrete sclerotic nodules seen in that condition (Fig. 14).

In addition to these sclerotic changes there were small areas of rarefaction in the inner portions of the medial femoral and tibial condyles.

\section{DISCUSSION}

In the radiographs of both these patients there are sclerotic changes in limb bones which show various patterns in different areas. Although none of these exactly fits classical descriptions, they resemble sufficiently the changes seen in osteopathia striata, osteopoikilosis and melorheostosis to suggest that both patients had a mixture of sclerosing bone dystrophies.

From a review of the literature it is evident that such mixtures are well recognised and that not all sclerosing dystrophies are distinct entities. In fact, it has been suggested that common factors may exist in their development.

Cocchi (1951) stated that melorheostosis may be confused with the striated form of osteopoikilosis although the striations and spots in melorheostosis are broader and larger. Caffey (1961) mentioned a patient in whom melorheostosis and osteopoikilosis were combined and he considered that the two syndromes have the same pathogenesis.

Hurt in 1953 reported a case of osteopathia striata with osteopetrosis, and there are several reports of other patients with mixed radiographic appearances (Nichols and Shiflett 1934, Lindbom 1942, Brailsford 1953, Gonet and Wright 1959).

Fairbank (1951) divided the sclerosing bone dystrophies into distinct compartments, and was unwilling to ascept a relationship between osteopathia striata and osteopoikilosis. Hurt (1953) discussed the possible relationship between these two conditions, and quoted several authors who believed that they were both manifestations of the same abnormal process.

It is interesting that microscopic examination of a portion of rib removed from Hurt's patient revealed dense bone with no recognisable specific characteristics. This was similar to the microscopic appearance of the dense areas found in the femoral epiphysis of the first patient reported in the present paper.

vol. 46 B, NO. 3, AUGUST 1964 
Neither of these two cases fits easily into a dogmatic classification. The first may be a late stage of unusually generalised melorheostosis, particularly as Morris, Samilson and Corley (1963) have said that deformities and limb inequalities occur in this condition. The second case was previously ascribed to melorheostosis; but in both there are features which suggest osteopoikilosis and osteopathia striata as well as melorheostosis.

The occurrence of the features of several of these rare sclerosing bone dystrophies in individual patients suggests that a common factor may be present at some stage in their development.

\section{SUMMARY}

1. A Nigerian patient with radiographic features of osteopathia striata, osteopoikilosis and melorheostosis is reported. Also radiographs of a patient from the Radiographic Museum of the Institute of Orthopaedics at the Royal National Orthopaedic Hospital are reproduced because they show a similar mixture of these conditions.

2. It is probable that a common factor is present at some stage in the development of melorheostosis, osteopathia striata, osteopoikilosis and possibly osteopetrosis.

Grateful thanks are due to Dr F. A. Trevethick and the Editor of the Lancet for permission to quote Case 2 to Dr E. H. Allen who has given constant encouragement and advice, to Dr H. A. Sissons who kindly reported on the sections, and to Mr F. Speed and Mr R. J. Whitley for the illustrations. Mr H. Jackson Burrows has very kindly read the manuscript.

\section{REFERENCES}

Brailsford, J. F. (1953): The Radiology of Bones and Joints. Fifth edition, p. 358. London: J. \& A. Churchill Ltd.

Caffey, J. (1961): Pediatric X-ray Diagnosis. Fourth edition, p. 925. Chicago: Year Book Medical Publishers Inc.

Cocchi, U. (1951): In Roentgen Diagnostics, by H. R. Schinz, W. E. Baensch, E. Friedl and E. Uehlinger. English translation arranged by J. T. Case. Vol. 1, p. 743. London: William Heinemann Medical Books Limited.

Fairbank, Sir T. (1951): An Atlas of General Affections of the Skeleton. Edinburgh and London: E. \& S. Livingstone Ltd.

Gonet, L. C. L., and WRIGHT, M. J. (1959): Hyperostosis Generalisata with Striations of Bones. British Journal of Radiology, 32, 818.

HURT, R. L. (1953): Osteopathia Striata-Voorhoeve's Disease. Journal of Bone and Joint Surgery, 35-B, 89.

LindBom. A. (1942): Zwei neue Fälle mit "streifenförmiger Osteopoikilie" (Voorhoeve). Acta Radiologica, 23, 296.

Morris, J. M., Samilson, R. L., Corley, C. L. (1963): Melorheostosis. Journal of Bone and Joint Surgery, 45-A, 1,191.

Nichols, B. H., and Shiflett, E. L. (1934): Osteopoikilosis. Report of an Unusual Case. American Journal of Roentgenology, 32, 52.

Trevethick, R. A. (1953): Melorheostosis. Lancet, i, 25. 